This article was downloaded by: [Duke University Medical Center]

On: 21 May 2015, At: 08:39

Publisher: Routledge

Informa Ltd Registered in England and Wales Registered Number: 1072954 Registered office: Mortimer House, 37-41 Mortimer Street, London W1T 3J H, UK

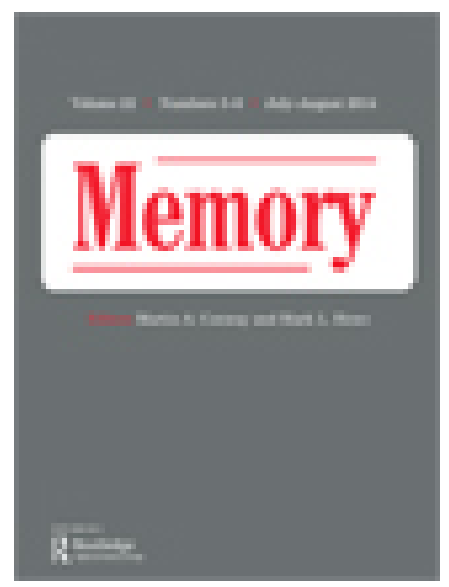

\title{
Memory
}

Publication details, including instructions for authors and subscription information:

http:// www. tandfonline.com/loi/ pmem20

\section{Inner speech and bilingual autobiographical memory: A Polish- Danish cross-cultural study}

Steen Folke Larsen ${ }^{a}$, Robert W. Schrauf ${ }^{b}$, Pia Fromholt ${ }^{c} \&$ David C. Rubin ${ }^{d}$

a University of Aarhus, Denmark

${ }^{b}$ Northwestern University Medical School, Chicago, USA

c University of Aarhus, and Centre for Gerontopsychology, Denmark

d Duke University, Durham, USA

Published online: 22 Sep 2010.

To cite this article: Steen Folke Larsen, Robert W. Schrauf, Pia Fromholt \& David C. Rubin (2002) Inner speech and bilingual autobiographical memory: A Polish-Danish cross-cultural study, Memory, 10:1, 45-54, DOI: 10.1080/09658210143000218

To link to this article: http:// dx.doi.org/ 10.1080/09658210143000218

\section{PLEASE SCROLL DOWN FOR ARTICLE}

Taylor \& Francis makes every effort to ensure the accuracy of all the information (the "Content") contained in the publications on our platform. However, Taylor \& Francis, our agents, and our licensors make no representations or warranties whatsoever as to the accuracy, completeness, or suitability for any purpose of the Content. Any opinions and views expressed in this publication are the opinions and views of the authors, and are not the views of or endorsed by Taylor \& Francis. The accuracy of the Content should not be relied upon and should be independently verified with primary sources of information. Taylor and Francis shall not be liable for any losses, actions, claims, proceedings, demands, costs, expenses, damages, and other liabilities whatsoever or howsoever caused arising directly or indirectly in connection with, in relation to or arising out of the use of the Content.

This article may be used for research, teaching, and private study purposes. Any substantial or systematic reproduction, redistribution, reselling, loan, sub-licensing, systematic supply, or distribution in any form to anyone is expressly forbidden. Terms \& Conditions of access and use can be found at http://www.tandfonline.com/page/termsand-conditions 


\title{
Inner speech and bilingual autobiographical memory: A Polish-Danish cross-cultural study
}

\author{
Steen Folke Larsen \\ University of Aarhus, Denmark \\ Robert W. Schrauf \\ Northwestern University Medical School, Chicago, USA \\ Pia Fromholt \\ University of Aarhus, and Centre for Gerontopsychology, Denmark \\ David C. Rubin \\ Duke University, Durham, USA
}

\begin{abstract}
Thirty years after fleeing from Poland to Denmark, 20 immigrants were enlisted in a study of bilingual autobiographical memory. Ten "early immigrators" averaged 24 years old at the time of immigration, and ten "late immigrators" average d 34 years old at immigration. Although all 20 had spent 30 years in Denmark, early immigrators reported more current inner speech behaviours in Danish, whereas late immigrators showed more use of Polish. Both groups displayed proportionally more numerous autobiographical retrievals that were reported as coming to them internally in Polish (vs Danish) for the decades prior to immigration and more in Danish (vs Polish) after immigration. We propose a culture- and language-specific shaping of semantic and conceptual stores that underpins autobiographical and world knowledge.
\end{abstract}

Many older adults emigrate, changing their physical and social environment as well as their language and culture. In cognitive terms (Rubin, Rahhal, \& Poon, 1998), in the immigrant's new environment, pre-migration memories are not cued as much by the once familiar surroundings that were part of the encoded events, and postmigration events require more effort after meaning, in part because both acculturation and language learning require considerable cognitive effort and portend extensive cognitive adjustment (Schrauf, 2000; Schrauf \& Rubin, 1998, 2000, in press-a). In social terms, the older immigrant may experience considerable change in social and economic status, while younger immigrants adapt more easily to new roles and employment (Yee, 1989). In this situation, older immigrants may lose their "sociocultural seniority" and experience immigration as a greater challenge to their identity and security.

To examine the effect of such changes, we studied two groups of Poles who emigrated to Denmark. Both groups emigrated between 1969 and 1971, and were tested in 1998, after about 30 years in Denmark. Participants in the study were recruited according to age at immigration, so that

Requests for reprints should be sent to Robert W. Schrauf, The Buehler Center on Aging, Northwestern University, 750 North Lake Shore Avenue, Chicago, IL 60611-1126, USA. Email: r-schrauf@northwestern.edu

We wish to thank the Danish Research Council for the Humanities for their grant to SFL, which funded the data collection, and NIA grant AG 16340-01 which funded the completion of this work after the untimely deaths of Steen Folke Larsen and Pia Fromholt.

We wish especially to thank the participants for their effort, Stainslaw Mielczarek for recruiting them, and Agnes Thuesen for testing them. 
a group of Early Immigrators were about 24 years old when they emigrated, and a group of Late Immigrators were 10 years older. Thus both groups had sufficient time in both locations while adults to develop an appreciation of both cultures, and both groups emigrated in what would otherwise have been a fairly stable period in cognitive development. The design given to us by nature confounds language, culture, and physical and social environment for the pre-migration years in Poland and again for the post-migration years in Denmark. Our design controls for the causes of immigration, language for pre-migration (Polish) and settlement (Polish and Danish), year of emigration, and the time spent in Denmark. The question we pose is the following: what happens to autobiographical memory when such a disruption in language and culture occurs? Unlike the more atomistic mnemonic traces often investigated in memory research-word lists and digit spans, for example-autobiographical event memories are more sensorially complex, temporally drawn out, and narratively structured (Conway \& PleydellPearce, 2000; Rubin, 1998; Rubin, Schrauf, \& Greenberg, 2001; Schrauf \& Rubin, in press-b). Because they are personal experiences tied to cultural contexts, they may also be inextricably linked at encoding to the languages of those cultural contexts. At retrieval, however, bilinguals can report the memories in as many languages as they speak (although one language may elicit more detailed or emotionally salient retrievals, Schrauf, 2000). If autobiographical memories are encoded in some language-specific manner, we cannot detect this simply by listening to memory reports. Bilinguals may mentally retrieve a memory in one language and narrate it in another. In other words, there may be an internal language of retrieval that differs from the external language of report.

An internal language of memory is one phenomenon among several similar phenomena all of which are instances of inner speech. Other examples of inner speech include: talking to oneself out loud, inner mental conversation, writing a note to oneself, counting, praying, and dreaming. Bilinguals are particularly interesting in this regard because they may engage in these activities in more than one language. Consecutive bilinguals-those who speak one language (the "mother tongue") and who, upon immigration, take up a second language-may experience a gradual displacement of one internal language by another. Indeed, this internal "first language attrition" (Seliger, 1996; Seliger \& Vago, 1991) may be a potent marker of full-scale cultural assimilation (Schrauf, in press).

Two strategies have been adopted in studies of the language of autobiographical memories among bilinguals. In one, the language of a memory is determined by asking individuals about what languages were spoken during the time of the event; in the other, the language of the memory is determined by asking participants in what language the memory came to them. In both kinds of studies bilinguals are cued with words in both of their languages and asked to think of a memory of a personal event in response to the cue. In the first kind of study, exemplified by Marian and Neisser (2000), Russian-English bilinguals were cued in both Russian and English and asked whether Russian or English "was spoken by, to, or around the participant" (p. 362) at the time of the event. If Russian was spoken at the time of the event, that memory was deemed a "Russian memory". Russian cues elicited more "Russian memories", English cues elicited more "English memories", suggesting language-dependent retrieval.

In the second type of study, exemplified by work by Schrauf and Rubin (1998, 2000; Schrauf, 2000), participants were asked to identify the language in which the memory came to them. Schrauf and Rubin reasoned that a bilingual can retrieve a memory in a particular language but report it in any language, and that the language in which a memory is actually recalled will more likely reflect the language in which it was originally encoded. In a first study with Spanish-English bilinguals, Schrauf and Rubin (1998) presented older Spanish-English speakers (who had migrated as adults) with cue words and asked them to identify any memory that seemed to come in the language opposite to the cue (e.g., "casa" elicits a memory that is judged to be retrieved in English). The resulting distributions of those "crossover" memories across the lifespan showed that "Spanish memories" commemorated events prior to immigration, "English memories" commemorated events after immigration.

In sum, previous experimental work with bilinguals suggests that the language of encoding remains effective at retrieval. In their study of young Russian-English bilinguals, Marian and Neisser found "language-dependent retrieval". That is, Russian cues triggered "Russian memories"; English cues triggered English memories. In their work with older Spanish-English bilinguals, Schrauf and Rubin found that memories for 
events that occurred prior to immigration were identified as having been internally retrieved in the first language.

In a study designed to characterise further the phenomenological properties of internal language retrievals, Schrauf and Rubin (2000) cued eight Spanish-English bilinguals who had immigrated to the USA at approximately 28.00 years of age (S.D. $=6.02$ ) with 16 cues in Spanish on one day and 16 cues in English on another. Participants noted whether memories seemed to come to them in Spanish or English or no language whatsoever, and whether or not explicit words were present. They further judged the intensity of sensory imagery, the presence/absence of "voices" in the memory, and the frequency of rehearsal. They identified the place and date of the event.

Memories were cued in the language of the day but identified by subjects as "coming to them" in either language (or no language) and subsequently reported in the language of the day. Thus, the protocol generated both non-linguistic and linguistic memories. Linguistic memories could be either congruent; that is, memories cued in one language were identified by subjects as retrieved in that same language, or crossover; that is, memories cued in one language were identified by subjects as retrieved internally in the other language.

Histograms displaying the distribution of memories over the lifespan showed similar patterns for both kinds of memories. For purposes of comparison with the data presented in this paper on Danish-Polish bilinguals, we reanalysed that Spanish-English data by grouping separately all Spanish retrievals and all English retrievals based on the internal language of retrieval (whether congruent or crossover). Memories were assigned to decades of life $(0-10,10-20,20-30,30-40,40-$ $50,50-60,60-70)$ according to reported age at time of event and sorted by internal language of retrieval. For each decade this produced a proportion of retrievals in Spanish and a proportion in English. The resulting curves are mirror images of each other: for example, if .80 of memories in the first decade of life are Spanish retrievals, then .20 of the memories for that same decade will be in English. Figure 1 shows the proportion of memories retrieved in Spanish only (and leaves unpictured the mirror-image curve representing retrievals in English). With age at immigration at approximately 28 years, the proportion of retrievals in Spanish is relatively high for the first three decades of life and drops precipitously after

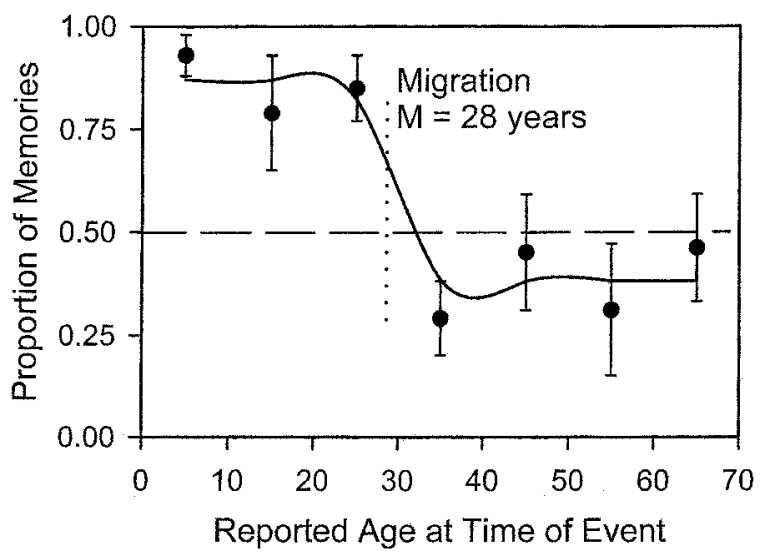

Figure 1. Proportion of retrievals for each decade of life identified as having come to participants in Spanish vs English (leaving unpictured the mirror-image English retrievals for each decade). Each participant $(n=8)$ received 16 cues in either language on alternative days. Error bars show standard errors.

immigration. This suggests that memories whose internal language is Spanish commemorate events that occurred "in Spanish".

While these results are promising, two valuable refinements are brought to this research by the present study. In the first place, the absolutely ideal way to test for language-specific memory encoding would be to recruit individuals who speak only one language long enough to develop a model of their cultural world and then change exclusively to a second language (completely dropping the first). "Cultural world" here comprises "the ideational realm that constitutes a culture-schemata, scripts, models, frames ... that are culturally constituted, socially distributed, and personally construed" (Poole, 1994, p. 833). In simple terms, such individuals would have One Code for One Cultural World, and Another Code for Another Cultural World (Schrauf, in press). Such a situation is rarely given in nature, however. Consecutive bilinguals typically speak one language (the "mother tongue") and after immigration both the first and second languages. The closest one can come to the ideal is to include in a study individuals who spoke the first language in the country of origin for many years with no admixture of the second language until immigration, followed by many years of practice in the second language.

Marian and Neisser's Russian-English speakers do not fit these criteria because their experience of the cultural worlds of Russia prior to immigration and the United States after immigration 
may be too brief to fit the "ideal" description just given. They were approximately 21.8 years old when tested and had immigrated to the United States only 7 years earlier at 14.3 years old. On the other hand, some of Schrauf and Rubin's SpanishEnglish speakers do not fit the criteria either, as some had school instruction in English as children, and so may have experienced some admixture of English with Spanish prior to immigration.

In the study reported here, the sample is composed of older Polish nationals who found themselves forced by political circumstances to migrate to Denmark around the ages of 25 to 35 . These individuals lived for many years in the first language and did not speak the second until migration. This "clean" break in linguistic and cultural experience approximates the "ideal" situation. In a sense, these are people with One Code for One Cultural World and Two Codes for a Second Cultural World.

A second benefit of this sample is that the Polish-Danish immigrants were recruited into two groups according to how old they were at the time of immigration (1969-1971). "Early Immigrators" were approximately 10 years younger at immigration than "Late Immigrators". This allows us to test the notion that individuals who were younger at immigration and who have spent more years in the second culture, speaking the second language, would show many more inner speech behaviours in the second language. In contrast, Late Immigrators should still show evidence of "thinking" in the mother tongue. Furthermore, regarding internal autobiographical retrievals, having two groups whose age at immigration differs by a decade sharpens our ability to detect changes in language-specific memory encoding because we know precisely when second-language acquisition began to take place for each group.

Given the unique affordances of this sample, we hypothesise the following. After childhood and youth in the country and language of origin, and after experiencing migration, acculturation, and second-language acquisition in early adulthood, Early Immigrators will show more evidence of inner speech in Danish (the second language); Late Immigrators will show more evidence of inner speech in Polish. Both groups will identify more memories as internally occurring in Polish for events prior to migration, and in Danish for events after immigration. Early Immigrators will show a decrease in Polish retrievals 10 years earlier (corresponding to age at immigration) than will Late Immigrators.

\section{METHOD}

Participants were 20 older native speakers of Polish who had immigrated to Denmark in the years 1969-1971. Most of these were state employees in Poland held responsible for the student revolt in the spring of 1968 and consequently fired from their positions. The majority were Jews who were used as scapegoats in this situation by the government. A group of Early Immigrators was recruited by selecting 10 participants whose average age at the time of immigration was 24.10 years (S.D. $=1.85$, range $20-26$ ), and a group of Late Immigrators by selecting 10 whose average age at immigration was 33.60 years (S.D. $=2.67$, range 30-36). At testing the average age of the Early Immigrators was 51.40 years (S.D. $=2.55)$ and that of the Late Immigrators 61.40 years $($ S.D. $=3.34)$. Thus, on average Late Immigrators were 9.5 years older at the time of immigration and 10.0 years older at testing. Each person participated in two days of testing separated by one week, one day in each language (counterbalanced). On each day, participants received 50 cue words in the language of the day. The general procedures were modelled on Schrauf and Rubin (1998) and used the same 100 words translated into Danish and Polish. Participants were asked to associate to each word a memory for an event from his or her life. Experimenters instructed that memories could be from long ago or from as recent as the current year, and that events recalled could be either important or trivial. Participants wrote a brief key-word description of each memory. After each recall, participants were asked if the memory seemed to come to them in Danish or in Polish, or if they simply weren't sure. After both sessions were completed, participants provided dates for each of the 100 possible events recalled. At the end of the final session, participants were asked to complete Language Background Questionnaires describing their use of Polish and Danish and self-rating their proficiencies in each language.

\section{RESULTS}

\section{Language proficiency}

The determination of language proficiency is notoriously complicated because available proficiency instruments tend to sample language behaviours underlying what Cummins (1984) calls 
Cognitive Academic Language Proficiency (CALP) versus Basic Interpersonal Communication Skills (BICS). CALP is a kind of proficiency proper to academic environments and tasks, and is usually learned in school settings. BICS is the kind of proficiency suitable for ordinary conversation, and is most often acquired naturally and outside organised instruction. Our interest is in the latter because avenues towards second-language acquisition for older immigrants are typically quite varied and the resulting proficiency is often highly serviceable but academically "unpolished". Given the lack of instruments appropriate to assessing this proficiency, we chose self-report as the method of assessment. What little research there is on the issue suggests that self-report can be a reliable predictor of proficiency (Dornic \& Ekehammar, 1988; Fishman \& Cooper, 1969).

Each participant provided self-ratings on 7point scales of his or her abilities on four components of language proficiency. Questions were as follows: How would you rate your proficiency in (understanding, speaking, reading, writing) in (Polish, Danish)? 1= Almost none, $2=$ Very poor, $3=$ Fair, $4=$ Functional, $5=$ Good, $6=$ Very good, $7=$ Like a native speaker. The results are shown in Table 1. A 2 (Early vs Late Immigrator) betweensubjects $\times 2$ (Polish vs Danish) within-subject ANOVA for the average rating on all four scales shows no main effect for immigration group, a main effect for language reflecting greater selfrated proficiency in Polish, $F(1,18)=60.13$, $M S E=7.24, p<.001$, and a significant interaction between group and language, $F(1,18)=5.52$, $M S E=7.24, p<.05$. The finding of no effect for group reflects the fact that Early vs Late Immigrators did not differ significantly in their selfratings of language proficiency in general (Early mean $=5.70$, S.D. $=1.02$; Late mean $=5.65$, S.D. =1.28). The main effect for language reflects the fact that participants' self-ratings in Polish $(\mathrm{M}=6.50$, S.D. $=.73)$ are significantly higher than their self-ratings in Danish $(\mathrm{M}=4.85$, S.D. $=.84)$. As can be seen in Table 1, the interaction is caused by a greater difference in proficiency in the two languages in the Late Immigrators.

\section{Years to second language competence}

In addition to self-ratings of language proficiency, participants were asked how long it took them to learn the second language. That is, they were
TABLE 1

Self-ratings of language proficiency in Polish and Danish

\begin{tabular}{lccccc}
\hline & \multicolumn{2}{c}{ Early } & & \multicolumn{2}{c}{ Late } \\
\cline { 2 - 3 } \cline { 5 - 6 } & Polish & Danish & & Polish & Danish \\
\hline Understand & 6.40 & 5.50 & & 6.80 & 5.00 \\
& $(.70)$ & $(.71)$ & & $(.42)$ & $(.94)$ \\
Speak & 6.30 & 5.00 & & 6.80 & 5.00 \\
& $(.82)$ & $(.94)$ & & $(.42)$ & $(.82)$ \\
Read & 6.50 & 5.70 & & 6.80 & 5.00 \\
& $(.97)$ & $(.82)$ & & $(.42)$ & $(.82)$ \\
Write & 5.90 & 4.30 & & 6.50 & 3.30 \\
& $(1.29)$ & $(1.34)$ & & $(.85)$ & $(1.42)$ \\
Totals & 6.28 & 5.13 & & 6.73 & 4.58 \\
& $(.96)$ & $(1.09)$ & & $(.55)$ & $(1.24)$ \\
\hline
\end{tabular}

Scores are means; scores in parentheses are standard deviations.

asked at what age they began learning Danish and at what age they felt they "could say just about anything in Danish that you can say in Polish" and "could speak Danish without thinking about it". Because second-language acquisition was occasioned by immigration itself, onset of language learning coincided with age at immigration. A sense of language competence in Danish for both groups followed approximately 7 years later (see Table 2). These individuals were clearly consecutive (vs simultaneous) bilinguals who lived the early years of life speaking Polish, becoming bilinguals in Polish and Danish after immigration.

\section{Languages of inner speech}

Remembering incidents from the past may sometimes involve either remembering in words, or memory for words heard or words spoken

TABLE 2

Age at immigration and subjective judgement of competence in Danish

\begin{tabular}{lcc}
\hline & $\begin{array}{c}\text { Age at } \\
\text { immigration }\end{array}$ & $\begin{array}{c}\text { Age at Danish } \\
\text { competence }\end{array}$ \\
\hline Early Immigrators & 24.10 & 31.80 \\
Late Immigrators & $(1.85)$ & $(4.47)$ \\
& 33.60 & 40.45 \\
& $(2.67)$ & $(7.37)$ \\
\hline
\end{tabular}

Scores are means; scores in parentheses are standard deviations. 
(Paivio \& Desrochers, 1991; Paivio \& Lambert, 1981; Schrauf \& Rubin, 2000). Thus, remembering involves inner speech in the same way as some other mental activities, for example, dreaming or talking to oneself. To gauge the bilinguals' relative use of inner speech in either language, each participant was asked to rate his or her use of both Polish and Danish in several mental activities in which inner speech plays a prominent role. Questions tapping this variable included the following:

1. When you write a note to yourself, in which language do you write it?

2. If you catch yourself thinking in words, which language is it?

3. In which language are you more comfortable expressing your feelings?

4. In which language do you dream?

5. When you talk to yourself, in which language do you do it?

6. Which language seems preferable for jokes?

Participants rated each language for each question on a 7-point scale as follows: $1=$ Never, $2=$ Occasionally, $3=$ Sometimes, $4=$ Half the time, $5=$ Most of the time, $6=$ Almost always, $7=$ Always. Average scores for inner speech for each language for each individual could range from 1-7. A 2 (Early vs Late Immigrator) between-subjects $\times 2$ (Polish vs Danish) withinsubject ANOVA shows no main effect for immigration group, no main effect for language (reflecting the flexible use of both languages in inner speech for these long-term immigrants), and a significant interaction between group and language, $F(1,18)=7.22, M S E=7.24, p<.05$. This interaction, as shown in Figure 2 suggests that, even given fluency in both languages, Late Immigrators more often find themselves using Polish in preference to Danish in spontaneous inner speech. Proficiency in Polish is not significantly correlated with inner speech behaviours in Polish $(r=.12, n s)$, but proficiency in Danish is highly correlated with inner speech behaviours in Danish $(r=.61 ; p<.05)$. The lack of correlation in Polish may be because the average ability to speak and understand is high in Polish (6.58 on a 7-point scale) compared to the average ability in Danish (5.12). Although there is enough variability to show a correlation, the level of proficiency in Polish may be good enough for the inner speech behaviours that were rated.

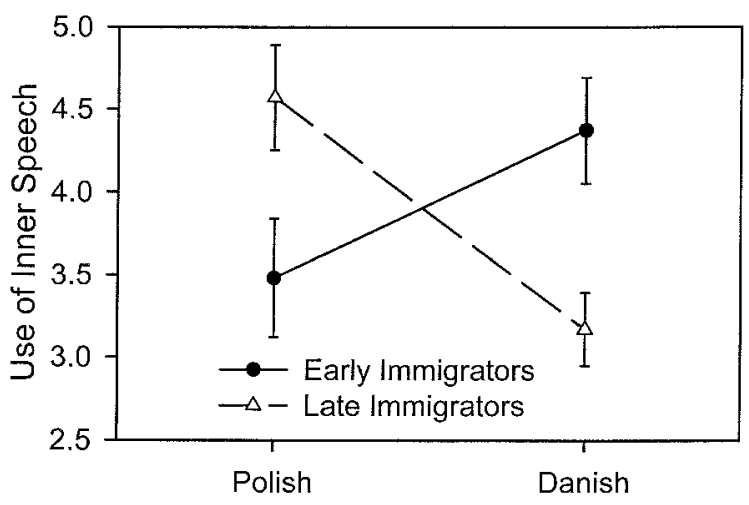

Language

Figure 2. Interaction between "Early" vs "Late" Immigrators and use of Polish vs Danish in inner speech behaviours. Although both groups had spent 30 years in Denmark since immigration, Early Immigrators were younger by 10 years at immigration (24.1 years old vs 33.6 years old).

\section{Distribution of autobiographical memories}

Analysis of memories retrieved by participants proceeded as explained earlier for the reanalysed Spanish-English data. Memories were arranged in histograms whose bins represented decades of life, and were displayed (within each bin) as proportions of memories recalled in Polish vs those recalled in Danish. Figure 3 shows the Polish data of Early Immigrators and Late Immigrators. Both groups show similarly shaped memory distributions: a higher proportion of retrievals in Polish

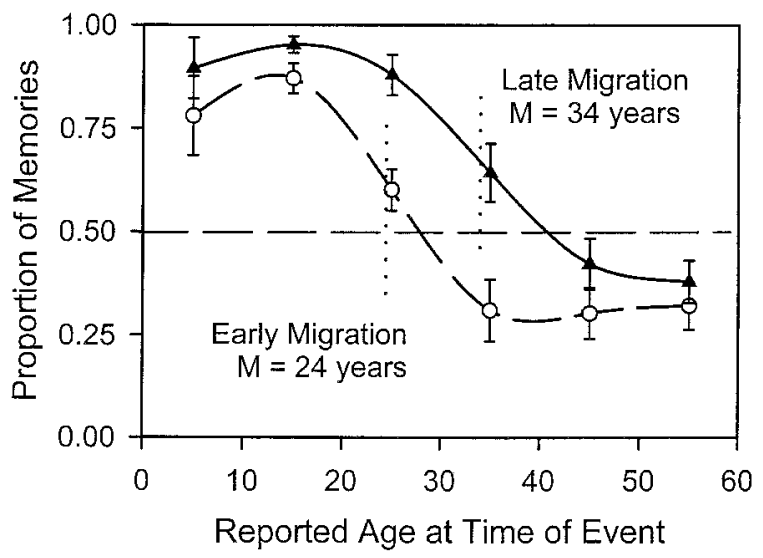

Figure 3. "Early Immigrators" immigrated to Denmark from Poland at a mean age of 24.1 years; "Late Immigrators" immigrated to Denmark at a mean age of 33.6 years. Both curves represent the proportion of memories retrieved in Polish per decade (leaving unpictured the mirror-image Danish retrievals). Error bars show standard errors. 
for the period preceding immigration and a decreased proportion of recalls in Polish for each decade after immigration. The decrease in Polish retrievals follows age at immigration, with Early Immigrators showing a dip in Polish recalls in the third decade of life and Late Immigrators showing the dip in the fourth decade of life. As both groups immigrated on average halfway through these respective decades (Early Immigrators at 24, Late Immigrators at 34), and as both groups took approximately 7 years to come to competence in Danish, the decades of immigration also include the most intense time of language learning. Thus, the context is set in subsequent decades for increased memory encoding in Danish and decreased encoding in Polish.

These patterns of self-ratings in language proficiency, self-ratings in practices of inner speech, and language-specific distributions of autobiographical memories may be summarised as follows. Early Immigrators rate themselves as more proficient in Danish than Late Immigrators. They also rate themselves as engaging in acts of inner speech in Danish more often than Late Immigrators. They show a decrease in the proportion of autobiographical retrievals in Polish (vs in Danish) in the decades following immigration. In contrast, Late Immigrators rate themselves as more proficient in Polish than do Early Immigrators and exhibit a greater likelihood to engage in acts of inner speech in Polish. Not surprisingly, they also show a decrease in the proportion of autobiographical retrievals in Polish after immigration, occurring 10 years later than the Early Immigrators.

\section{DISCUSSION}

One of the strengths of this study is the historical fact that the Polish émigrés to Denmark were not anticipating their immigration, acculturation, and second-language acquisition. Their move to Denmark was forced on them by circumstances in a relatively short space of time. From the cognitive and psycholinguistic perspectives of this paper, this means that these persons cognised their physical and social environments from birth through early adulthood in Polish, and subsequently and abruptly began to learn to do so in Danish. Given this situation, memories for events that occurred in Poland should be retrieved in Polish while memories for events in Denmark should be retrieved in Danish, and this is what we see. By displaying proportions of autobiographical recalls by language of recall in each decade of life, we have shown that retrievals in Polish drop off after immigration (and correspondingly increase in Danish). By extension, however, once in Denmark, the participants cognise their physical and social environments increasingly in Danish and less so in Polish. The self-ratings of language proficiency and habits of inner speech provide support for this view. Early Immigrators (but less so Late Immigrators) rate themselves as more proficient in Danish and engage in more acts of inner speech in Danish. Put simply, they are thinking in Danish more extensively than their Late Immigrator counterparts.

A second strength of this study is that participants were recruited into two groups differing on age at immigration by 10 years. This decade-span difference makes it possible to test further the hypothesis that autobiographical retrieval is language-specific cognition, because "nature" has manipulated for us the moment of immigration, acculturation, and second-language acquisition. Our results show a proportional decrease in firstlanguage retrievals and a proportional increase in second-language retrievals starting with the decade following immigration. Late Immigrators show the pattern 10 years later than Early Immigrators. Interestingly, both groups had lived in Denmark for 30 years by the time of testing, and therefore had the same exposure to Danish.

In line with our earlier work (Schrauf \& Rubin, 1998, 2000) and that of Marian and Neisser (2000), these considerations suggest that at least some autobiographical memories are encoded in some linguistic form, perhaps in words (Paivio \& Desrochers, 1991; Paivio \& Lambert, 1981 ), or that memory traces include some linguistic elements (pragmatic, phonological, morphological) that feature in encoding-specificity (Tulving \& Thompson, 1973) and subsequent retrieval. Such a language-specific view of encoding and retrieval places in question the current modular approach to cognitive processing that separates language from memory.

Let us take a simplistic modular view that suggests that memories are held in some non-linguistic store and verbally encoded by a language module according to the retrieval requirements of the situation. In bilingualism, for example, the current Revised Hierarchy Model (Kroll \& DeGroot, 1997) of bilingual memory posits a nonlinguistic Conceptual Store linked to a linguistic Lexicon A (e.g., first language) and Lexicon B 
(e.g., a second language), with links between the Lexicons (accounting for translation). This model implies that language is reduced to its ostensive function. That is, language is just a question of "applying names" to mental images (found in the Conceptual Store). This may be adequate for linking the lexical entry "chair" to the prototypical mental image "chair", but such a simplistic view cannot account for the complexity of memory for autobiographical events.

Take, for instance, two retrieval scenarios: one, the memory for a simple event, the other, the memory for a more complex event. A very simple, autobiographical memory might well be completely imagistic and require no language either at encoding or (internally) at retrieval. To remember walking along the beach is just such a memory. It would be entirely possible for a cartoonist to represent such a memory in one frame with no dialogue, no captions, no words whatsoever. The mind might well act in an analogous fashion, preserving images and no words. Telling the memory would, of course, require words, and the "naming function" would be invoked, but it is easy to imagine remembering the event in a moment of mental solitude with no words whatsoever. However, for any more complex memory, the "meaning making" and sequencing necessary would seem to require language. To remember that I was walking along the beach on the Caribbean island of Nevis looking for a fisherman to take me across the channel back to St. Kitts, because I missed the last launch back to St. Kitts and had nowhere to stay on Nevis for the night, and had to catch a plane back to San Juan early in the morning: this is a complex autobiographical memory which would very likely be impossible for the cartoonist to render without dialogue or language. Nor, we would argue, can the mind do it. Given the complexity of the object-that is, given that autobiographical memories are more sensorially complex, temporally drawn out, and narratively structured-and given that personal experiences are intimately linked to cultural contexts, the role that language plays must be integral. That is, what autobiographical memory there could be without language would be so hermeneutically impoverished as to be unrecognisable as autobiographical memory. If, then, memory and language are so intimately tied, the question is how to understand the "presence" of language in the memory trace, especially at the level of the Conceptual Store, where no language has been seen before.
In recent work on conceptual representation in bilingualism, Pavlenko (1999) distinguishes lexical, semantic, and conceptual levels in bilingual memory. Whereas previous models of bilingual memory collapse the semantic into the conceptual, this model separates word meaning (semantic level) from mental representation (the conceptual level). In partial support for this approach Pavlenko cites work by Lecours and Joanette (1980) and Paradis (1997) on global and paroxysmal aphasia, in which patients lose their abilities to produce and comprehend language but nevertheless retain the ability to act in accord with lexicalised distinctions. "A subject with such an impairment is able to categorize along the linguistically internalized lines and buy a 'mug' instead of a 'cup,' but has no way of processing words and accessing their meanings" (Pavlenko, 1999 , p. 211). Here, conceptual representation is distinct from word meaning (the semantic level) but shaped by it, and hence culturally and contextually variable.

Bilingualism, linked essentially to biculturalism, offers another window onto the same dynamic. Whereas a monolingual-monocultural might have completely co-extensive and commensurate semantic and conceptual representations, the immigrant has a far more complex set of relations between semantic and conceptual systems. As conceptual representations formed in one cultural context (the homeland) are challenged by second-language acquisition and acculturation in another culture (the "new country"), they may interact in a number of ways. Older conceptions may co-exist with new conceptual representations, they may shift in scope and amplitude in the direction of new cultural dimensions, or they may converge towards wholly new representations different from both the first and second language/cultures. Pavlenko suggests that episodic memory, in the form of bilingual autobiographical memory, may be one area in which mental representations might simply co-exist. For our purposes, this suggests that a "Polish memory" commemorating an event from childhood in Poland might well be represented at conceptual and imagistic levels in associational networks that are stored "along linguistically internalised lines". These are in turn linked to semantic associations proper to the Polish lexicon. The retrieval of such a memory representation might begin at the conceptual level, triggered by a cue, and proceed to activate Polish semantic 
associations (word meanings) and corresponding Polish lexical forms (words). Finally, the participant makes the judgement that he or she "remembered in Polish".

This explanation suggests that individuals who migrated in adulthood have co-existing sets of memory representations (at the specifically conceptual level): one for life in the homeland, linked to the semantic and lexical systems of the mothertongue and another for life in the culture of adoption, linked to the semantic and lexical systems of the second language.

\section{CONCLUSION}

The data of this paper suggest that older immigrants who migrated from Poland to Denmark in mid-life seem to retrieve memories internally in specific languages: Polish for events that occurred before an unplanned and unanticipated emigration, Danish for events that occurred afterwards. In the framework of cognitive ageing we might ask: does second-language acquisition in mid-life have specifiable effects on autobiographical retrieval in later life? It seems it does.

The findings of this paper, however, relate to the larger issue of the relation between thought and language. There is little doubt that some portion of conscious thinking is thinking in words, particularly in words of what philosophers call "natural language" (versus, e.g., "mentalese"). That is, some thinking takes place in the language(s) that one speaks. Some philosophers in fact suggest that thought is inextricably linked to language (e.g. Cavell, 1993; Wittgenstein, 1953) or that at least all conscious thought takes place in natural language (Carruthers, 1996, 1998). Memories may be one more instance of explicitly linguistic inner speech and may be intimately linked to natural language as well. Older adults who immigrated to other countries provide a unique window onto the relation of memory and language, because these individuals have encoded the world of the homeland in one language and the "new world" in another language. From the viewpoint of memory research we might ask: does thought covary with language? The answer, we suggest, is that it does.

Manuscript received 20 March, 2001 Manuscript accepted 28 March 2001

\section{REFERENCES}

Carruthers, P. (1996). Language, thought, and consciousness: An essay in philosophical psychology. Cambridge: Cambridge University Press.

Carruthers, P. (1998). Thinking in language? Evolution and a modularist possibility. In P. Carruthers \& J. Boucher (Eds.), Language and thought: Interdisciplinary perspectives (pp. 94-114). Cambridge: Cambridge University Press.

Cavell, M. (1993). The psychoanalytic mind: From Freud to philosophy. Cambridge, MA: Harvard University Press.

Conway, M.A., \& Pleydell-Pearce, C.W. (2000). The construction of autobiographical memories in the self-memory system. Psychological Review, 107, 261-268.

Cummins, J. (1984). Bilingualism and special education: Issues in assessment and pedagogy. Austin, TX: Pro-Ed.

Dornic, S., \& Ekehammar, B. (1988). Note on self-rated second language proficiency. Perceptual and Motor Skills, 66, 40-42.

Fishman, J.A., \& Cooper, R.L. (1969). Alternative measures of bilingualism. Journal of Verbal Learning and Verbal Behavior, 8, 276-282.

Kroll, J.F., \& de Groot, A.M.B. (1997). Lexical and conceptual memory in the bilingual: Mapping form to memory in two languages. In A.M.B. de Groot \& J.F. Kroll (Eds.), Tutorials in bilingualism: Psycholinguistic perspectives (pp. 169-199). Mahwah, NJ: Lawrence Erlbaum Associates Inc.

Lecours, A., \& Joanette, Y. (1980). Linguistic and other aspects of paroxysmal aphasia. Brain and Language, $10,1-23$.

Marian, V., \& Neisser, U. (2000). Language-dependen t recall of autobiographical memories. Journal of Experimental Psychology: General, 129, 361-368.

Paivio, A. (1991). Dual coding theory: Retrospect and current status. Canadian Journal of Psychology, 45, 255-287.

Paivio, A., \& Desrochers, A. (1991). A dual coding approach to bilingual memory. In A. Paivio (Ed.), Images in mind: The evolution of a theory (pp. 327341). New York: Harvesters Wheatsheaf.

Paivio, A., \& Lambert, W. (1981). Dual coding and bilingual memory. Journal of Verbal Learning and Verbal Behavior, 20, 532-539.

Paradis, M. (1997). Representation lexicale et conceptuelle chez les bilingues: deux langues, trois systemes. In J. Auger \& Y. Rose (Eds.), Explorations du lexique (pp. 15-27). Quebec: CIRA1.

Pavlenko, A. (1999). New approaches to concepts in bilingual memory. Bilingualism: Language and Cognition, 2, 209-230.

Poole, F.J.P.P. (1994). Socialization, enculturation and the development of personal identity. In T. Ingold (Ed.), Companion encyclopedia of anthropology (pp. 831-890). New York: Routledge.

Rubin, D.C. (1998). Beginnings of a theory of autobiographical remembering. In C.P. Thompson, D.J. Herrman, D. Bruce, J.D. Read, D.G. Payne, \& M.P. Toglia (Eds.), Autobiographical memory: Theoretical and applied perspectives (pp. 47-67). Mahwah, NJ: Lawrence Erlbaum Associates Inc. 
Rubin, D.C., Rahhal, T.A., \& Poon, L.W. (1998). Things learned in early adulthood are remembered best. Memory and Cognition, 26, 3-19.

Rubin, D.C., Schrauf, R.W., \& Greenberg, D. (2001). Remembering, reliving, and believing autobiographical memories: Inter- and intra-individual analyses. Manuscript submitted for publication.

Schrauf, R.W. (2000). Bilingual autobiographical memory: Experimental studies and clinical cases. Culture \& Psychology, 6, 387-417.

Schrauf, R.W. (in press). Comparing cultures withinsubjects: A cognitive account for acculturation as a framework for cross-cultural study. Anthropological Theory.

Schrauf, R.W., \& Rubin, D.C. (1998). Bilingual autobiographical memory in older adult immigrants: A test of cognitive explanations of the reminiscence bump and the linguistic encoding of memories. Journal of Memory and Language, 39, 437-457.

Schrauf, R.W., \& Rubin, D.C. (2000). Internal languages of retrieval: The bilingual encoding of memories for the personal past. Memory and Cognition, $28,616-623$.

Schrauf, R.W., \& Rubin, D.C. (in press-a). Effects of voluntary immigration on the distribution of autobiographical memories over the lifespan. Applied Cognitive Psychology.
Schrauf, R.W., \& Rubin, D.C. (in press-b). On the bilingual's two sets of memories. In R. Fivush \& C. Haden (Eds.), Connecting culture and memory: The development of an autobiographical self. Mahwah, NJ: Lawrence Erlbaum Associates Inc.

Seliger, H.W. (1996). Primary language attrition in the context of bilingualism. In W.C. Ritchie \& T.K. Bhatia (Eds.), Handbook of second language acquisition (pp. 605-626). san Diego: Academic Press.

Seliger, H.W., \& Vago, R.M. (1991). The study of first language attrition: An overview. In H.W. Seliger \& R.M. Vago (Eds.), First language attrition (pp. 3-15). New York: Cambridge University Press.

Tulving, E., \& Thompson, D.M. (1973). Encoding specificity and retrieval processes in episodic memory. Psychological Review, 80, 352-373.

Wittgenstein, L. (1953). Philosophical investigations. Oxford: Blackwell.

Yee, B.W.K. (1989). Loss of one's homeland and culture during the middle years. In R.A. Kalish (Ed.), Midlife loss: Coping strategies (pp. 281-300). Newbury Park, CA: Sage. 